\title{
Incidental detection of a small solid pseudopapillary neoplasm of the pancreas after a traffic accident in a |2-year-old girl: a case report
}

This article was published in the following Dove Press journal:

International Medical Case Reports Journal

19 October 2015

Number of times this article has been viewed

\section{Younglim Kim}

Suk-Bae Moon

Department of Surgery, Kangwon National University Hospital, Kangwon National University School of Medicine, Chuncheon, South Korea
Correspondence: Suk-Bae Moon Department of Surgery, Kangwon National University Hospital, Kangwon National University School of Medicine, Chuncheon, 200-722, South Korea

Tel +82 332589209

Fax +82 332582169

Email sukbae75.moon@gmail.com
Abstract: Solid pseudopapillary neoplasm (SPN) is a rare tumor of the pancreas that tends to grow silently in patients at a young age, to a large size and mass. We report here a case of a small-sized SPN detected incidentally in a 12-year-old girl following a traffic accident. The tumor was $3.5 \mathrm{~cm}$ in maximal diameter and was found to have hemorrhagic necrosis without a solid component. Laparoscopic spleen-preserving distal pancreatectomy was performed which cured the patient. SPN is generally accepted to be a low grade malignant tumor, but its clinical behavior is sometimes unpredictable. Tumor size and the proportion of solid portion of the tumor have both recently been identified as predictors of malignancy. Although the initial presentation in this case was that of the traffic accident, the subsequent detection of a small, totally cystic SPN, and then the complete eradication of the lesion, led to a favorable outcome for the patient. Long-term monitoring should prevent any chance of recurrence.

Keywords: pancreatic neoplasm, children, distal pancreatectomy

\section{Introduction}

Solid pseudopapillary neoplasm (SPN) is a low grade malignant neoplasm of the pancreas typically occurring in younger women. Patients with SPN are often clinically asymptomatic and the tumors are not detected by standard imaging modalities until they are large enough to cause symptoms. ${ }^{1,2}$ We report herein a case of a small SPN detected incidentally after a traffic accident, which nevertheless eventually resulted in a favorable outcome for the patient.

\section{Case report}

The case review was conducted according to all guidelines outlined in the Declaration of Helsinki. As this study involved no interventional experimentation whatsoever and is a retrospective review of a case, written consent from the patient was not required. A 12-year-old girl presented to the emergency department shortly after a traffic accident with upper abdominal pain. She had been in the passenger seat of the car, wearing a seat belt. She had no associated symptoms such as nausea or vomiting. Her past medical history was unremarkable. On physical examination, the patient had an acutely-ill-looking appearance but her vital signs were within normal ranges. Her abdomen was flat and slightly tender in the upper abdominal region but without signs of peritonitis. There were no identifiable external wounds on her abdomen. On laboratory examination, the white blood cell count was 12,100 cells/uL (normal, 4,000-10,000 cells $/ \mathrm{uL}$ ) with $88 \%$ segmented neutrophils, and hemoglobin was $11.6 \mathrm{~g} / \mathrm{dL}$ (normal, 13.3-16.5 g/dL). Liver function tests were normal. Serum amylase 
and lipase were $86 \mathrm{U} / \mathrm{L}$ (normal, 30-118 U/L) and $33 \mathrm{U} / \mathrm{L}$ (normal, 12-53 U/L), respectively. Abdominal computed tomography (CT) scan revealed neither free gas nor blood in her abdomen, but a $4 \mathrm{~cm}$ mass was detected in the tail of the pancreas, and the patient was hospitalized for further evaluation of the pancreatic mass. The mass had an enhancing thin wall, and the internal texture was homogeneously cystic without enhancing solid components (Figure 1). CEA and CA-125 checked after admission were $1.2 \mathrm{ng} / \mathrm{mL}$ (normal, 0-5 ng/mL) and $10.9 \mathrm{U} / \mathrm{mL}$ (normal, 0-35 U/mL), respectively. On day 2 of hospital admission, the patient underwent a laparoscopic spleen-preserving distal pancreatectomy to rule out malignancy. The tumor was found to be grossly $3.5 \mathrm{~cm}$ in maximal diameter, with a fibrous capsule with extensive hemorrhagic necrosis internally (Figure 2A). Pathological examination confirmed the diagnosis of SPN by demonstrating the characteristic pseudopapillae in which residual tumor cells appear to rosette around the vascular cores (Figure 2B). The resection margin was free of tumor cells. The postoperative course was uneventful and the patient was discharged 7 days after the operation. Currently, 6 months postoperative, the patient is well without radiological evidences of disease recurrence.

\section{Discussion}

SPN is an uncommon pancreatic epithelial tumor that usually occurs in women in the second to fourth decades of life, usually presenting with a tumor size large enough to affect adjacent organs and provoke symptoms such as discomfort and vague abdominal pain. ${ }^{3}$ In an adult study, the author noted that the mean diameter of the SPN was $10 \mathrm{~cm}$ and that the large size could be used as a diagnostic tool for detecting SPNs. ${ }^{4}$ In a recent pediatric series, the median maximum tumor diameter was $5.5 \mathrm{~cm}$, ranging from 1.8 to $15 \mathrm{~cm} .{ }^{5}$ The patient in this case had no abdominal symptoms before the accident and because the tumor was too small to cause mass-related symptoms, the eventual diagnosis of SPN in this patient would otherwise have been considerably delayed.

SPN is a low grade malignant neoplasm with an excellent long-term outcome after complete surgical excision. Hwang et al found that malignant SPNs tend to be larger than benign tumors (median $10 \mathrm{~cm}$ vs median $5 \mathrm{~cm}$ ) with a greater proportion of solid components (median $88.5 \%$ vs $41.5 \%$ ) at presentation. ${ }^{5}$ However, it remains contentious as to whether SPNs show malignant transformation as they grow larger or whether those SPNs with innate malignant potential tend to grow more solid and larger. Moreover, there have been exceptional cases showing unpredictable behavior; some patients have shown long-term survival with residual SPN, ${ }^{6,7}$ while in others aggressive SPN has proved ultimately fatal. ${ }^{8,9}$ Therefore, to our knowledge, the benign nature shown by most SPNs does not justify or excuse late detection or treatment delay. The patient described here had a small SPN that had no malignant foci and given that long-term monitoring is mandatory for this low grade malignant tumor, the seemingly unfortunate accident experienced by the patient paradoxically resulted in a positive outcome for her.

Treatment of choice for SPN is complete surgical excision, with the actual surgical procedure dependent on the location of the tumor. SPNs can occur throughout the pancreas, but are typically found more frequently in the body or tail region ${ }^{10}$ and can be managed by distal pancreatectomy. In children, compared to the adults, less destructive surgery has been advocated and tumor enucleation had been tried in a 16-year-old girl who had SPN in both the head and tail of the pancreas. ${ }^{11}$ However, contrary to the case reported by Juric et al, ${ }^{11}$ the patient described here had a single mass at the most distal part of the pancreas and, moreover, concerns on the potential malignant foci led us to consider distal pancreatectomy rather than simple enucleation. With advances in surgical techniques, laparoscopic distal pancreatectomy

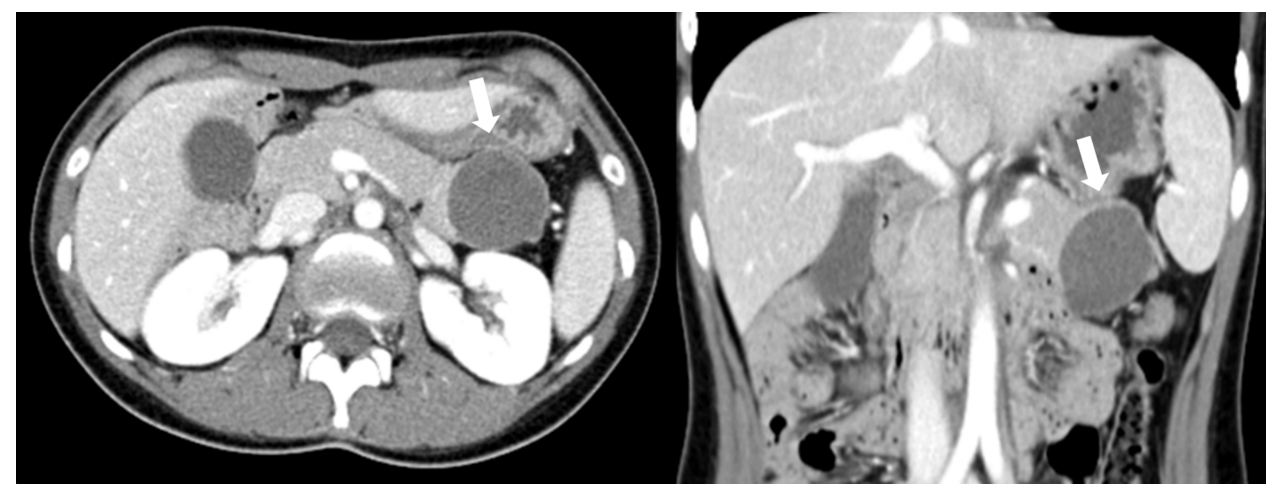

Figure I CT scan of mass in the pancreatic tail region with a homogeneously cystic component with enhancing thin wall (arrows). Abbreviation: CT, computed tomography. 

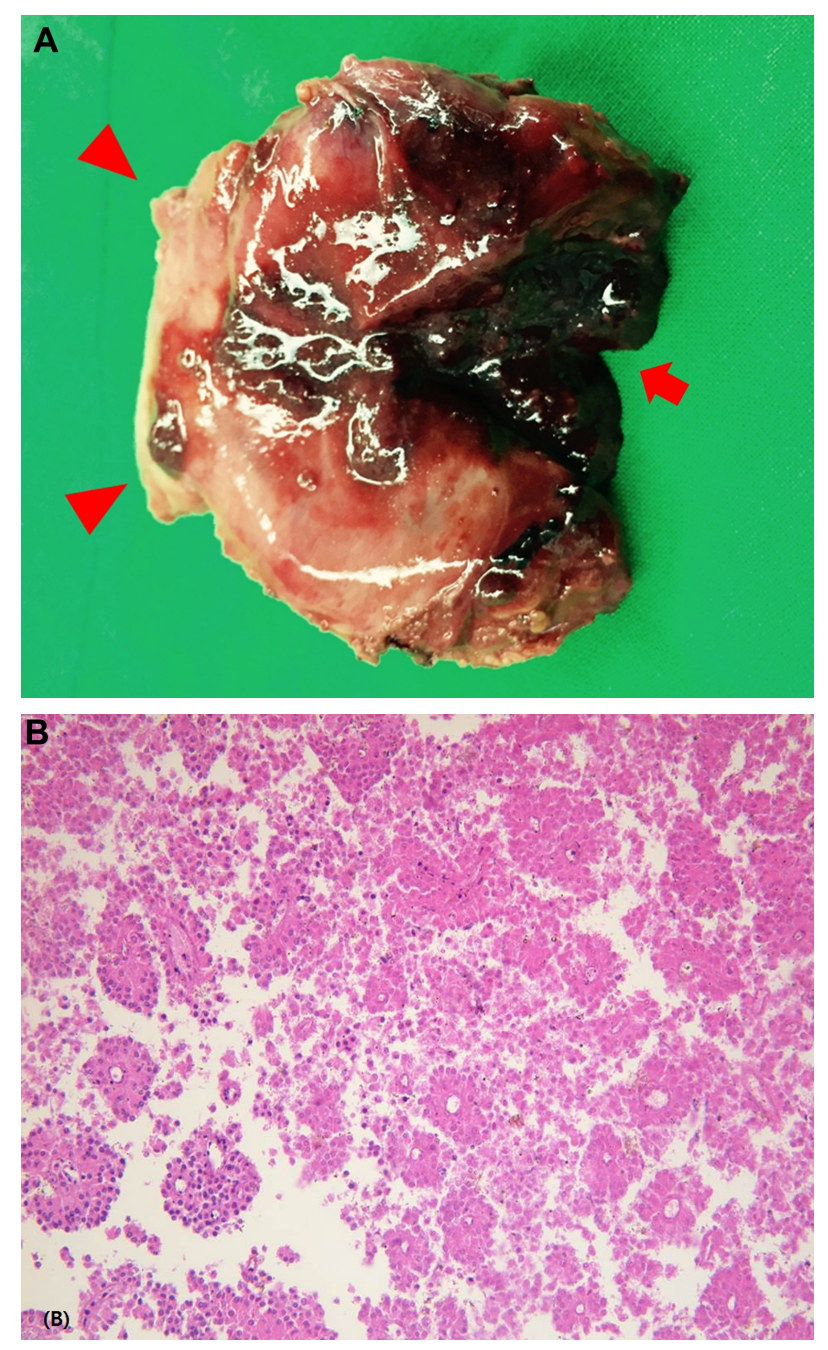

Figure 2 Surgical specimen and microphotograph.

Notes: (A) Area of extensive hemorrhagic necrosis is seen (arrow) with normal pancreatic tissue at resection margin (arrowheads). (B) Microphotograph shows the characteristic pseudopapillary rosette of tumor cells (hematoxylin and eosin, $\times 200$ ).

has proven to be as safe and effective as conventional open surgery. ${ }^{12}$ As SPNs frequently occur in younger women who are sensitive to cosmetic appearances, minimally invasive surgery could be an excellent alternative in such cases, provided complete tumor removal is guaranteed. Due to the possible occurrence of occult postsplenectomy infection, whether splenectomy is performed should also be considered in the management of SPN of the tail region of the pancreas in pediatric patients. In this case, spleen-preserving laparoscopic distal pancreatectomy successfully treated the patient by excising the tumor while preserving the spleen.

In summary, we successfully treated pancreatic tail SPN in a 12-year-old girl. Owing to the abdominal trauma presentation, the tumor was detected incidentally at an early stage of tumor growth. Laparoscopic spleen-preserving distal pancreatectomy produced the best results both from an oncologic as well as cosmetic aspect. Considering that malignancy is related to the tumor size and the proportion of the solid portion, prognosis of this patient appears promising, but long-term follow-up should be provided.

\section{Disclosure}

The authors report no conflicts of interest in this work.

\section{References}

1. Cantisani V, Mortele KJ, Levy A, et al. MR imaging features of solid pseudopapillary tumor of the pancreas in adult and pediatric patients. AJR Am J Roentgenol. 2003;181(2):395-401.

2. Choi JY, Kim MJ, Kim JH, et al. Solid pseudopapillary tumor of the pancreas: typical and atypical manifestations. AJR Am J Roentgenol. 2006;187(2):W178-W186.

3. Jiang L, Cui L, Wang J, Chen W, Miao L, Jia J. Solid pseudopapillary tumors of the pancreas: findings from routine screening sonographic examination and the value of contrast-enhanced ultrasound. J Clin Ultrasound. 2015;43(5):277-282.

4. Choi BI, Kim KW, Han MC, Kim YI, Kim CW. Solid and papillary epithelial neoplasms of the pancreas: CT findings. Radiology. 1988;166(2):413-416.

5. Hwang J, Kim DY, Kim SC, Namgoong JM, Hong SM. Solidpseudopapillary neoplasm of the pancreas in children: can we predict malignancy? J Pediatr Surg. 2014;49(12):1730-1733.

6. Zinner MJ, Shurbaji MS, Cameron JL. Solid and papillary epithelial neoplasms of the pancreas. Surgery. 1990;108(3):475-480.

7. Nishihara K, Nagoshi M, Tsuneyoshi M, Yamaguchi K, Hayashi I. Papillary cystic tumors of the pancreas. Assessment of their malignant potential. Cancer. 1993;71(1):82-92.

8. van den Akker M, Angelini P, Taylor G, Chami R, Gerstle JT, Gupta A Malignant pancreatic tumors in children: a single-institution series. J Pediatr Surg. 2012;47(4):681-687.

9. Martin RC, Klimstra DS, Brennan MF, Conlon KC. Solid-pseudopapillary tumor of the pancreas: a surgical enigma? Ann Surg Oncol. 2002; 9(1):35-40.

10. Coleman KM, Doherty MC, Bigler SA. Solid-pseudopapillary tumor of the pancreas. Radiographics. 2003;23(6):1644-1648.

11. Jurić I, Pogorelić Z, Stepan JG, Kuzmić IP. Extremely rare presentation of Frantz's tumour: synchronous localisation in the pancreatic head and tail. Scott Med J. 2014;59(3):e8-e12.

12. Velanovich V. Case-control comparison of laparoscopic versus open distal pancreatectomy. J Gastrointest Surg. 2006;10(1):95-98.

International Medical Case Reports Journal

\section{Publish your work in this journal}

The International Medical Case Reports Journal is an international, peer-reviewed open-access journal publishing original case reports from all medical specialties. Previously unpublished medical posters are also accepted relating to any area of clinical or preclinical science. Submissions should not normally exceed 2,000 words or

4 published pages including figures, diagrams and references. The manuscript management system is completely online and includes a very quick and fair peer-review system, which is all easy to use. Visit http://www.dovepress.com/testimonials.php to read real quotes from published authors. 